\title{
Aneurysms of the vein of Galen
}

\author{
D O'DONNABHAIN AND D F DUFF
}

\author{
Our Lady's Hospital for Sick Children, Dublin
}

SUMMARY Six neonates with aneurysms of the vein of Galen are described: five were associated with an intracerebral arteriovenous fistula and presented with heart failure in the neonatal period; one had hydrocephalus at birth. Two infants died from intractable cardiac failure within 48 hours of age and two from progressive hydrocephalus and cardiac failure at 8 months and 8 years respectively. Two of the infants had copper coil embolisation of the aneurysm-one has since died of an intracerebral haemorrhage. The diagnosis of an intracerebral arteriovenous fistula should be considered in any infant presenting with unexplained heart failure. Close attention to the volume of all arterial pulses, and the venous pulse in the neck as well as auscultation of the head for a cranial bruit may suggest the diagnosis, which can then be substantiated by cerebral ultrasound.

Aneurysms of the vein of Galen are rare congenital abnormalities that have been diagnosed more often at necropsy than in life. ${ }^{12}$ There is often an associated arteriovenous malformation draining into the aneurysm. The clinical presentation depends on (a) the size of the aneurysm, which if large may compress the aqueduct of Sylvius and the posterior end of the third ventricle, causing hydrocephalus and (b) the magnitude of blood flow through any associated arteriovenous fistula. In most instances there is a large arteriovenous shunt which causes cardiac failure.

The results of surgical and non-surgical management of this latter group is extremely difficult and is associated with a high mortality. Recently, however, some success has been reported with copper coil embolisation of the aneurysms. ${ }^{3}$ Early diagnosis is therefore necessary so that such treatment can be electively planned.

In this report we describe six cases of vein of Galen aneurysms seen in the last 15 years, four between June 1986 and April 1988, showing the various modes of presentation. The clinical signs and investigations used to establish the diagnosis are also described.

\section{Case reports}

Table 1 summarises the clinical presentation and course of the infants and table 2 shows the investigations performed.

CASE 1 (INDEX CASE)

A boy, born at full term and weighing $3200 \mathrm{~g}$, was

Table 1 Clinical presentation and course

\begin{tabular}{|c|c|c|c|c|c|c|}
\hline & Case 1 & Case 2 & Case 3 & Case 4 & Case 5 & Case 6 \\
\hline $\begin{array}{l}\text { Congestive cardiac failure } \\
\text { Pulse volume }\end{array}$ & $\begin{array}{l}+ \\
\text { Peripheral } \downarrow \downarrow \\
\text { Carotid } \uparrow \uparrow\end{array}$ & $\begin{array}{l}+ \\
\text { Peripheral variable } \\
\text { Carotid } \uparrow\end{array}$ & $\bar{\uparrow}$ & $\begin{array}{l}+ \\
\text { Normal }\end{array}$ & + & $\stackrel{+}{\text { No record }}$ \\
\hline Cranial bruit & + & + & - & + & + & + \\
\hline Seizures & + & - & - & - & + & + \\
\hline Cerebral haemorrhage & - & - & - & $+^{*}$ & - & - \\
\hline Outcome & $\begin{array}{l}\text { Died at } \\
2 \text { days }\end{array}$ & $\begin{array}{l}\text { Died at } \\
1 \text { day }\end{array}$ & Alive & $\begin{array}{l}\text { Died at } \\
3 \text { months }\end{array}$ & $\begin{array}{l}\text { Died at } \\
8 \text { months }\end{array}$ & $\begin{array}{l}\text { Died at } \\
8 \text { years }\end{array}$ \\
\hline
\end{tabular}

$+/-$ Present/absent; $\uparrow$ increased, $\downarrow$ decreased.

*Occurred six weeks after embolisation procedure. 
Table 2 Investigations

\begin{tabular}{|c|c|c|c|c|c|c|}
\hline & Case 1 & Case 2 & Case 3 & Case 4 & Case 5 & Case 6 \\
\hline Electrocardiography & Normal & * & No record & $\begin{array}{l}\text { Right axis deviation, } \\
\text { right ventricular } \\
\text { hypertrophy }\end{array}$ & Normal & Normal \\
\hline $\begin{array}{l}\text { Heart size by } \\
\text { chest radiography }\end{array}$ & Increased & Increased & Normal & Increased & Increased & Increased \\
\hline $\begin{array}{l}\text { Two dimensional } \\
\text { echocardiography }\end{array}$ & $\begin{array}{l}\text { Increased right } \\
\text { heart, increased } \\
\text { carotids, patent } \\
\text { foramen ovale, } \\
\text { patent ductus } \\
\text { arteriosus }\end{array}$ & $\begin{array}{l}\text { Increased right } \\
\text { heart, patent } \\
\text { foramen ovale, } \\
\text { heart, patent } \\
\text { ductus arteriosus }\end{array}$ & $*$ & $\begin{array}{l}\text { Atrial septal } \\
\text { defect }\end{array}$ & $*$ & $*$ \\
\hline Cerebral ultrasound & Aneurysm & Aneurysm & $\begin{array}{r}\text { Aneurysm, } \\
\text { increased } \\
\text { ventricles }\end{array}$ & Aneurysm & $*$ & $*$ \\
\hline $\begin{array}{l}\text { Cardiac } \\
\text { catheterisation }\end{array}$ & $*$ & * & $*$ & $\begin{array}{l}\text { Arteriovenous } \\
\text { malformation }\end{array}$ & $*$ & $*$ \\
\hline $\begin{array}{l}\text { Cerebral } \\
\text { angiography }\end{array}$ & $*$ & $*$ & $\begin{array}{l}\text { Arteriovenous } \\
\text { malformation, } \\
\text { aneurysm }\end{array}$ & $\begin{array}{l}\text { Arteriovenous } \\
\text { malformation, } \\
\text { aneurysm }\end{array}$ & $\begin{array}{l}\text { Arteriovenous } \\
\text { malformation, } \\
\text { aneurysm }\end{array}$ & $\begin{array}{l}\text { Arteriovenous } \\
\text { malformation, } \\
\text { aneurysm }\end{array}$ \\
\hline $\begin{array}{l}\text { Computed } \\
\text { tomgraphy }\end{array}$ & $*$ & $*$ & $\begin{array}{l}\text { Arteriovenous } \\
\text { malformation, } \\
\text { aneurysm }\end{array}$ & Aneurysm & $*$ & * \\
\hline
\end{tabular}

${ }^{*}$ Not performed.

delivered vaginally to a 27 year old primigravida after an uneventful pregnancy. His Apgar scores were 2 at 1 minute, 6 at 5 minutes, and 9 at 10 minutes. He required intubation and intermittent positive pressure ventilation for five minutes. By 30 minutes he was acyanotic, and had no signs of cardiac failure, but was acidotic. His head circumference was on the 50th centile. A chest radiograph showed cardiomegaly while an electrocardiogram was within normal limits (table 2).

By 18 hours of age he had developed signs of congestive cardiac failure with very low volume peripheral pulses. A diagnosis of hypoplastic left heart was suspected and he was transferred to the cardiac unit at Our Lady's Hospital.

On examination he was an ill, lethargic, distressed baby who was grey in colour. All pulses, except the carotids, were of reduced volume. He had prominent venous and arterial neck pulsations. The heart sounds were palpable. On auscultation there was evidence of pulmonary hypertension and a gallop rhythm. A systolic ejection murmur was heard widely over the precordium, maximal at the lower left sternal border. There was a prominent continuous bruit over the neck vessels, and softer over the cranium (table 1). The clinical impression was of cardiac failure secondary to a cerebral arteriovenous malformation.

Echocardiography (table 2) showed a dilated innominate vein and superior vena cava, an enlarged right atrium and right ventricle, and large

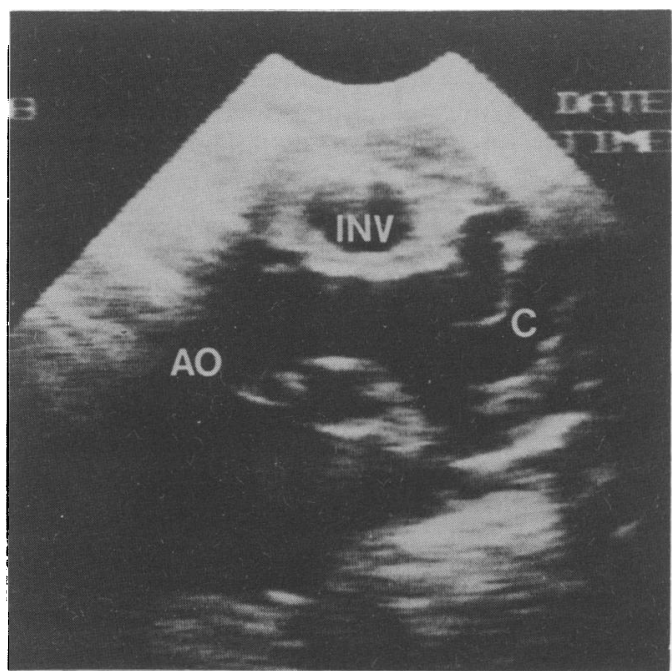

Fig 1 Case 1. Two dimensional echocardiograph showing aortic arch $(A O)$ with dilated tortuous carotid arteries $(C)$ and engorged innominate vein (INV).

tortuous carotid arteries (fig 1). There was also a patent foramen ovale and ductus arteriosus. Cerebral ultrasound showed a large central echo free cystic lesion which displaced the lateral ventricles (fig 2). 


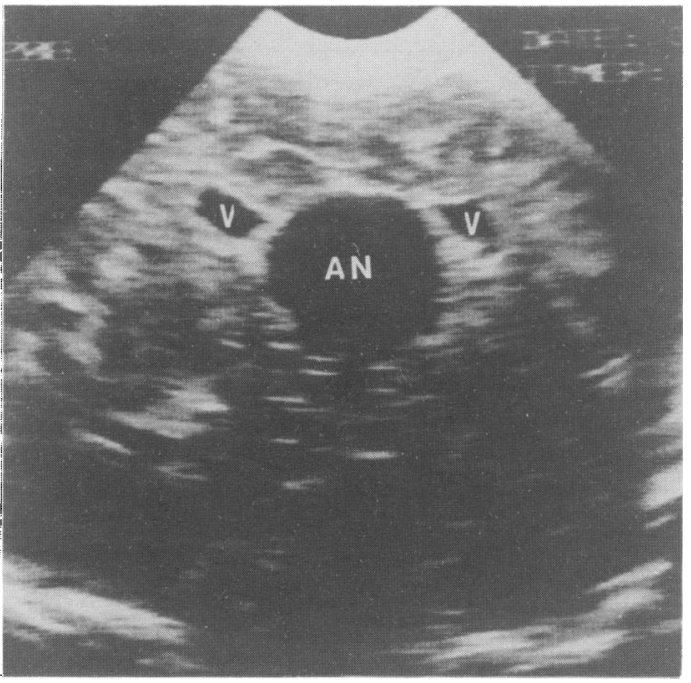

Fig 2 Case 1. Cerebral ultrasound-short axis. Large central cystic lesion $(A N)$ displaces lateral ventricles $(V)$.

Neurological and neurosurgical opinions were obtained. Surgery was not considered feasible in view of the baby's critical condition. Over the next 24 hours the baby's condition deteriorated. He had an episode of left sided twitching. He became progressively more tachypnoeic, cyanosed, and oedematous, and died at 2 days of age.

Necropsy of the brain showed that there was a large arteriovenous malformation draining into an aneurysm of the vein of Galen. The feeding arterial vessels arose from the basilar system, and the lateral, straight, and sigmoid sinuses were engorged.

\section{CASE 2}

A boy, born at full term and weighing $4300 \mathrm{~g}$, was delivered vaginally to a 21 year old primigravida. There was shoulder dystocia and the Apgar scores were 4 at 1 minute and 9 at 5 minutes. Bounding pulses were noted at birth and oxygen was administered by mask because of 'poor' colour. There was facial suffusion with petechiae and central cyanosis. The infant was transferred to Our Lady's Hospital at 9 hours of age with suspected cyanotic congenital heart disease. On examination the infant was acutely ill, and lethargic with mild central cyanosis, tachypnoea, and mild dyspnoea. The head circumference was on the 90th centile but was appropriate for this infant's size. The pulse volume was normal with a slightly brisk quality but not bounding. The carotid pulse was easily felt but also not bounding. The venous pulsation in the neck was very prom- nent. There was a significant increase in right ventricular activity and on auscultation an ejection click and loud pulmonary closure sound indicating severe pulmonary hypertension. An ejection systolic murmur, grade III/VI in intensity, was heard widely over the precordium and a continuous murmur was easily appreciated over the carotid arteries and cranium. The liver was engorged and palpable 3.0 $\mathrm{cm}$ below the right costal margin. On the chest radiography there was appreciable cardiomegaly with congested lungs.

A diagnosis of a cerebral arteriovenous malformation was suspected and confirmed on cerebral ultrasound, which showed a large vein of Galen aneurysm. The echocardiogram showed a large right atrium and ventricle, mild dilatation of the innominate vein and superior vena cava. The carotid arteries were not tortuous and enlarged as in case 1 . There was an associated patent ductus arteriosus and atrial septal defect. Supportive care only was given as neither surgery nor coil embolisation was considered feasible. The infant died at 24 hours of age.

\section{CASE 3}

A boy, born at full term and weighing $3800 \mathrm{~g}$, was delivered vaginally after an uneventful pregnancy to a 38 year old mother of four. His Apgar scores were 9 at 1 minute and 10 at 5 minutes. Routine examination showed his head circumference to be $39 \mathrm{~cm}$; this was greater than the 90th centile for his gestational age.

Cerebral ultrasound showed a central echo free cystic lesion compressing the aqueduct of Sylvius (fig 3 ). He was seen by the paediatric neurologist

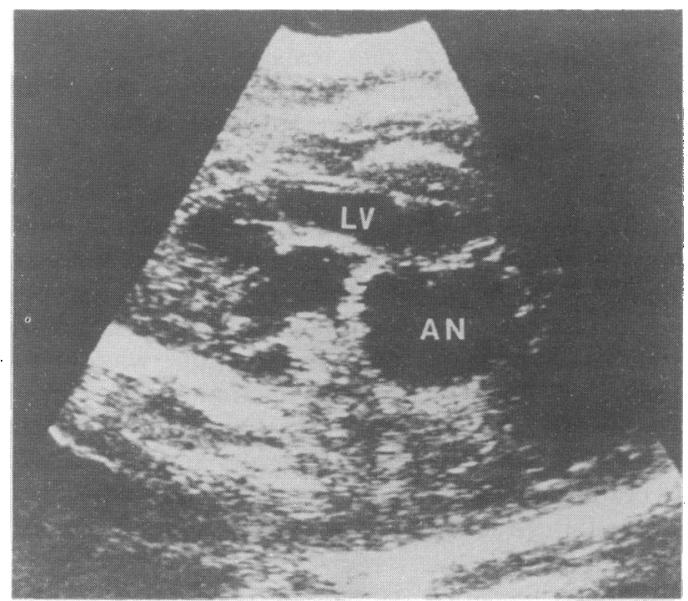

Fig 3 Case 3. Cerebral ultrasound-long axis. Large echo free lesion $(A N)$ and dilated lateral ventricles $(L V)$ above. 


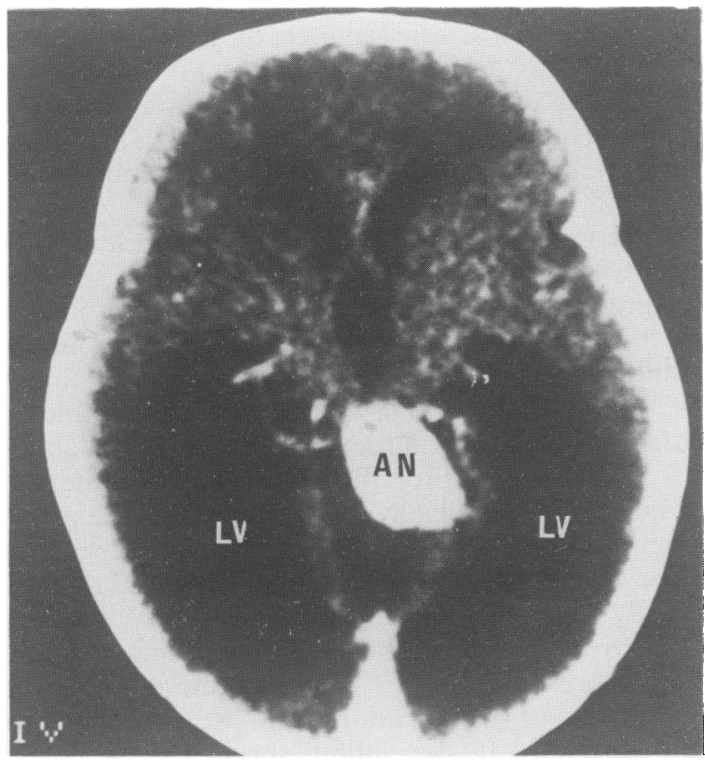

Fig 4 Case 3. Computed tomogram with contrast, axial view. Arteriovenous malformation draining into the aneurysm $(A N)$ of the vein of Galen, which drains into the straight sinus. The dilated lateral ventricles $(L V)$ are also seen.

and referred for contrast computed tomography, which confirmed hydrocephalus with dilatation of the lateral and third ventricles and an aneurysm of the vein of Galen, obstructing the aqueduct of Sylvius (fig 4). Cerebral angiography confirmed the presence of an associated small arteriovenous malformation draining into the vein of Galen. Initial neurological examination was otherwise normal.

Cardiological examination at 3 weeks of age showed signs of a hyperdynamic circulation without cardiac failure. A cranial bruit was not heard.

The baby developed progressive hydrocephalus necessitating the insertion of a ventriculoperitoneal shunt at 5 weeks of age. This was followed by the first part of a staged embolisation procedure at 6 weeks of age in which copper coils were introduced into the aneurysm under imaging intensification control.

$\mathrm{He}$ is clinically well at 2 years of age, apart from mild developmental delay.

\section{CASE 4}

A boy, born at full term and weighing $3270 \mathrm{~g}$, was delivered vaginally to a 25 year old primigravida. His Apgar scores were 4 at 1 minute and 10 at 5 minutes.
The baby was transferred to the neonatal intensive care unit as he was tachypnoeic. He was found to be acyanotic with a head circumference greater. than the 50th centile.

He became more tachypnoeic and was transferred to Our Lady's Hospital at 2 days of age. On examination he was tachnpnoeic with intercostal recession. On auscultation there was evidence of pulmonary hypertension and a systolic murmur was audible over the pulmonary area. A chest radiograph showed cardiomegaly and increased pulmonary vascularity. On an electrocardiogram right axis deviation, right atrial enlargement, and right ventricular hypertrophy were shown. Echocardiography showed an atrial septal defect of the secundum type.

$\mathrm{He}$ was treated with digoxin and diuretics. His tachypnoea settled initially. Over the next three weeks he continued to have episodes of tachypnoea and cyanosis. A cardiac catheterisation was performed at 4 weeks of age. An intracranial arteriovenous malformation with an aneurysm of the vein of Galen was visualised after a left ventricular angiogram (table 2).

He was seen by the paediatric neurologist. The baby's head circumference had grown along the 50th centile and a cranial bruit was heard. A central cystic lesion was seen on cerebral ultrasound.

The baby was transferred to the neurosurgical unit at another hospital where an arteriovenous malformation draining into the vein of Galen was confirmed on cerebral angiography. He had the first part of a staged embolisation procedure similar to case 3 at 6 weeks of age. At 3 months of age the baby developed seizures and died from massive intracranial haemorrhage.

\section{CASE 5}

A girl, aged 5 weeks, born in 1976 in New Zealand to Irish parents was admitted with failure to thrive and convulsions. She had been feeding poorly and was drowsy for several days before admission. The doctor who referred her to hospital witnessed episodes of fitting, staring, and stiffening, which had not been noticed by her parents.

On admission she was having frequent seizures. Her head circumference was on the 50th centile. She was acyanotic, her pulses were described as jerky; and her liver was enlarged. The precordium was hyperactive. On auscultation there was a systolic murmur along the left sternal border, and a loud cranial bruit was heard. An electrocardiogram was normal for her age. A chest radiograph showed cardiomegaly. She was treated with digoxin, diuretics, and anticonvulsants. When stable, cerebral angiography was performed at 6 weeks of age: this showed a large central arteriovenous malformation 
draining into an aneurysm of the vein of Galen. In consultatation with a neurologist and a neurosurgeon her lesion was considered inoperable so she was managed conservatively.

Her family moved home to Ireland soon after the diagnosis was made and she was admitted to Our Lady's Hospital. She had evidence of severe developmental delay, developed progressive hydrocephalus, and died at 8 months of age.

\section{CASE 6}

A 3 day old boy, born in 1973, was transferred from a maternity hospital with signs of cardiac failure. He was tachypnoeic, with intercostal recession and an enlarged liver. His head circumference was greater than the 50th centile. There was a systolic murmur along the left sternal edge. A chest radiograph showed cardiomegaly and evidence of pneumonia. An electrocardiogram was within normal limits for age. He was treated with digoxin, diuretics, and antibiotics to which he had a good response. He was thought to have a ventricular septal defect. When reviewed at 11 weeks of age he was well. His weight and head circumference were just above the 90th centile.

When seen at 8 months his head circumference was considerably greater than the 90 th centile. His scalp veins were dilated and he had slight proptosis of his right eye. A cranial bruit was heard. He was referred to the neurosurgical unit at another hospital where he had carotid angiography: this showed an arteriovenous malformation in the region of the right lateral ventricle draining into an aneurysm of the vein of Galen. The aneurysm was obstructing the aqueduct of Sylvius.

At 13 months posterior fossa exploration was attempted with a view to ligating some of the feeding vessels, but haemorrhage was so severe that the operation was abandoned. Despite the apparently hopeless outlook after the failed surgery he survived until 8 years of age. In the intervening years he developed a progressive hemiplegia but had only mild developmental delay. He developed spastic quadriplegia in the last months of his life and died of pneumonia.

\section{Discussion}

The vein of Galen, or great cerebral vein, is formed by the union of the two internal cerebral veins. It drains into the straight sinus. Arteriovenous malformations are congenital vascular anomalies that vary greatly in size. They consist of a convoluted mass of blood vessels fed by large arteries and drained by increasingly large veins. Aneurysmal dilatation of the vein of Galen occurs when one or more abnormal arteries connect directly into it. As a result of this arteriovenous connection a shunt is established. This lesion is quite different from arteriovenous malformations elsewhere in the brain, where aneurysmal dilatation of the draining veins does not occur.

Arteriovenous malformations may present with symptoms at any age from infancy to the sixth or seventh decade but most commonly cause problems in the age group of 25 to 35 years. The initial manifestations are usually haemorrhage in about $50 \%$ of cases, seizures in 25 to $30 \%$, focal neurologic deficit in 3 to $5 \%$, and recurrent headaches in about $5 \%{ }^{4}$ When the presentation occurs in infancy, however, and especially in the newborn, the arteriovenous malformation is usually associated with an aneurysm of the vein of Galen and because there is usually a large blood flow through the consequent arteriovenous fistula, heart failure dominates the clinical presentation. ${ }^{3}{ }^{5-8}$ This presentation was evident in five of the six children who were admitted to this hospital. If the infant survives and if the magnitude of blood flow through the fistulous communication is not large, the aneurysm of the vein of Galen may obstruct the aqueduct of Sylvius leading to hydrocephalus. Case 3 was unusual in that hydrocephalus was evident at birth. Older children may present with headaches, focal seizures, or subarachnoid haemorrhage. Intraventricular haemorrhage is a rare complication. ${ }^{9}$ Intracranial haemorrhage occurred in only one of our cases and that event happened six weeks after embolisation treatment.

The clinical diagnosis of a cerebral arteriovenous fistula as a cause of congestive cardiac failure in the newborn may be difficult but is possible if close attention is paid to certain crucial clinical signs. Bilateral prominent venous and arterial pulsations in the neck were clearly evident in our recent cases and may have been present in the earlier cases though not noted. These clinical signs may be overlooked in the neonate because of the short neck and the laxity of the tissues in this area, unless the infant is propped up and the head extended. The importance of palpating the carotid pulse is highlighted by the often fluctuating volume of the peripheral pulses. While the peripheral pulse is usually described as bounding in quality there may be considerable variation between cases as well as in the individual case at different times (for example, case 2). In case 1 the volume of the peripheral pulse was so poor that the hypoplastic left heart syndrome was suspected until the bounding carotid pulse was appreciated. This cardiocerebral steal was also evident in case 2 , though to a lesser degree. The cranial bruit is the other important clinical sign and 
was noted in five of the six infants described. According to Hughes a benign systolic cranial bruit may be found in $15 \%$ of normal infants and children under the age of 5 years. ${ }^{10}$ The cranial bruit in the presence of an arteriovenous malformation, however, is continuous and while usually soft is audible dominantly over the parietal areas of the skull and may be heard over most of the posterior cranial vault. The continuous bruit may also be noted over the neck vessels.

When the diagnosis is suspected clinically two dimensional ultrasound, with or without contrast of the heart and brain, provides a rapid and efficient method for the detection of an aneurysm of the vein of Galen. ${ }^{2}$ Echocardiography may help to exclude a structural cardiac defect and indirectly suggest the possibility of the diagnosis of a cerebral arteriovenous malformation by the observation of a dilated innominate vein, superior vena cava, and enlarged tortuous carotid arteries, which have increased pulsation. Cranial ultrasound clearly shows the aneurysm of the vein of Galen as an echo free space, which, if compressing the aqueduct of Sylvius will be associated with dilatation of the lateral ventricles as shown in case 3. Selective arteriograms or computerised tomography may be reserved for detailed anatomical studies of the arteriovenous malformation before surgery.

Surgery for this condition is difficult and rarely successful, though there have been some encouraging results recently. ${ }^{256}$ The two main approaches are obliteration of the feeding vessels and the use of emboli. Mickle and Quisling described the procedure in which vein of Galen aneurysms are embolised with copper coils. ${ }^{3}$ Two of their three patients had a satisfactory outcome, and one of our patients is clinically well, though with mild developmental delay two years after the procedure.

While the newborn infant continues to pose major management problems, early diagnosis of the mal- formation is essential if a planned surgical or embolic approach, or both, is to be undertaken before the infant is in a critical state. Close attention to clinical signs and the use of echocardiography and cerebral ultrasound should facilitate an early and definitive diagnosis of this rare though important anomaly.

The authors thank Drs J McMenamin, W Gorman, B Denham, and E Tempany and Professor O'Donohoe for permission to include their patients. We also thank Dr J Kelleher of the radiology department at Our Lady's Hospital and Dr J Toland of the radiology department and $\mathrm{Mr} \mathrm{S}$ O'Briain of the neurosurgery department at the Richmond Hospital for their assistance.

\section{References}

${ }^{1}$ Norman MG, Beckler LE. Cerebral damage in neonates resulting from arteriovenous malformation of the vein of Galen. J Neurol Neurosurg Psychiatry 1974;37:253-8.

${ }^{2}$ Snider AR, Scott JS, Silverman NH. Detection of intracranial arteriovenous fistula by two dimensional ultrasound. Circulation 1981;63:1179-85.

${ }^{3}$ Mickle JP, Quisling RG. The transtorcular embolization of Galen aneurysms. J Neurosurg 1986;64:731-5.

${ }^{4}$ Kelly DL. Arteriovenous malformations of the brain. Current concepts of cerebrovascular disease. Stroke 1972;7:7-9.

${ }^{5}$ Hoffman HJ, Chuang S, Hendrick EB, et al. Aneurysm of the vein of Galen. Experience at the Hospital for Sick Children Toronto. J Neurosurg 1982;57:316-22.

${ }^{6}$ Claireaux AE, Newman CGH. Arteriovenous aneurysm of the great vein of Galen with heart failure in the neonatal period. Arch Dis Child 1960;35:605-12.

7 Watson DG, Smith RR, Brann AW. Arteriovenous malformation of the vein of Galen. Am J Dis Child 1976;130:520-5.

${ }^{8}$ Holden AM, Fyler DC, Shillito J, et al. Congestive heart failure from intracranial arteriovenous fistula in infancy. Pediatrics 1972;48:30-9.

9 Schum TR, Meyer GA, Grausz JP, Glaspey JC. Neonatal intraventricular haemorrhage due to an intracranial arteriovenous malformation-a case report. Pediatrics 1979;64:242-4.

${ }^{10}$ Hughes R, Todd RM. Intracranial bruits in infants and children. Arch Dis Child 1953;28:198.

Correspondence to Dr DF Duff, Our Lady's Hospital for Sick Children, Crumlin, Dublin 12, Republic of Ireland.

Accepted 16 June 1989 